\title{
Escala diagramática para avaliação da severidade da antracnose em bastão do imperador
}

\author{
Diagrammatic scale for assessment of torch ginger anthracnose severity
}

\author{
Beatriz Meireles Barguil ${ }^{\mathrm{I}}$ Igor Corrêa Lima Albert ${ }^{\mathrm{I}}$ Sami Jorge Michereff ${ }^{\mathrm{I}^{*}}$ \\ Sônia Maria Alves de Oliveira ${ }^{\mathrm{I}}$
}

\begin{abstract}
A antracnose, causada pelo fungo Colletotrichum RESUMO gloeosporioides (Penz.) Sacc., é uma importante doença do
bastão do imperador [Etlingera elatior (Jack) Smith] no
Nordeste brasileiro. Considerando a inexistência de métodos
padronizados para quantificação dessa doença, foi elaborada
uma escala diagramática com os níveis $1,2,4,8,16,32,64$,
82 e $92 \%$ de área da bráctea lesionada, testando-se a acurácia,
a precisão e a reprodutibilidade das estimativas de severidade
da antracnose com e sem a utilização da escala. A escala
diagramática foi validada por 10 avaliadores, usando 45
brácteas com diferentes níveis de severidade da antracnose.
Sem a escala, a maioria dos avaliadores superestimou a
severidade da doença. Com a escala, os avaliadores obtiveram
melhores níveis de acurácia e precisão, com os erros absolutos
concentrando-se na faixa de $10 \%$. Os avaliadores apresentaram
elevada repetibilidade (95\%) e reprodutibilidade ( $\geq 90 \%$ em
$75,6 \%$ dos casos) das estimativas com a utilização da escala.
A escala diagramática proposta demonstrou ser adequada
para avaliação da severidade da antracnose em bastão do
imperador.
\end{abstract}

Palavras-chave: Etlingera elatior, Colletotrichum gloeosporioides, fitopatometria.

\section{ABSTRACT}

Anthracnose caused by the fungus Colletotrichum gloeosporioides (Penz.) Sacc. is an important disease of torch ginger [Etlingera elatior (Jack) Smith] in the Brazilian Northeast. Considering the inexistence of standard methods for assessment of this disease, a diagrammatic scale was developed with 1, 2, 4, 8, 16, 32, 64, 82 and 92\% of diseased bracts area and tested for accuracy, precision and reproducibility of the estimative of anthracnose severity with and without using the scale. The diagrammatic key was validated by 10 raters, using 45 bracts with different levels of severity. Without the diagrammatic scale most of raters overestimated disease severity. With the scale raters obtained better levels of accuracy and precision, with absolute errors concentrated around $10 \%$. Raters showed great repeatability (95\%) and reproducibility ( $\geq 90 \%$ in $75.6 \%$ of cases) of estimative by using the scale. The proposed diagrammatic scale was suitable for the evaluation of torch ginger anthracnose severity.

Key words: Etlingera elatior, Colletotrichum gloeosporioides, phytopatometry.

O bastão do imperador [Etlingera elatior (Jack) Smith] é uma espécie vegetal com elevado valor ornamental, que possui inflorescências grandes com coloração vermelha, rosa ou rosa-claro. Em Pernambuco, a qualidade das inflorescências pode ser seriamente comprometida pela ocorrência da antracnose, causada pelo fungo Colletotrichum gloeosporioides (Penz.) Sacc. Os sintomas ocorrem inicialmente nas brácteas florais externas e, posteriormente, nas internas, caracterizando-se por lesões encharcadas, deprimidas e com formato elíptico, seguidas de necrose de coloração escura (LINS \& COELHO, 2003).

Apesar da importância da antracnose em bastão do imperador no Nordeste brasileiro, inexistem

IDepartamento de Agronomia, Universidade Federal Rural de Pernambuco (UFRPE). Av. Dom Manoel de Medeiros, s/n, 52171900, Recife, PE, Brasil. E-mail: sami@depa.ufrpe.br. *Autor para correspondência. 
métodos padronizados para quantificação dessa doença, o que limita a realização de estudos epidemiológicos e de comparação de medidas de controle.

Um sistema de quantificação de doença bemsucedido deve propiciar resultados acurados, precisos e reprodutíveis. A acurácia refere-se à proximidade de uma estimativa a um valor real de quantidade de doença avaliada. A precisão refere-se à variação ou repetibilidade associadas com uma estimativa e reprodutibilidade refere-se à ausência de variação em estimativas quando a mesma amostra de doença é avaliada por outro avaliador (NUTTER JR. \& SCHULTZ, 1995).

Como a quantificação da severidade das doenças é estimada visualmente, ela está sujeita a grande subjetividade e pode induzir graves erros. Várias estratégias têm sido propostas para minimizar a subjetividade das estimativas de severidade, dentre as quais se destacam as escalas diagramáticas, que consistem na representação ilustrada de uma série de plantas, folhas ou partes de plantas com sintomas em diferentes níveis de severidade (BERGAMIN FILHO \& AMORIM, 1996). Nesse contexto, este trabalho teve como objetivos desenvolver uma escala diagramática para avaliação da severidade da antracnose em bastão do imperador e analisar os níveis de acurácia, precisão e reprodubilidade das estimativas geradas com sua utilização.

Para elaboração da escala diagramática, foram coletadas 100 brácteas externas de bastão do imperador (cv. Red Torch) em plantios comerciais no município de Paulista, PE, com diferentes níveis de severidade de antracnose. As brácteas foram digitalizadas a 200dpi e, com auxílio do programa Assess $^{\circledast}$ (The American Phytopathological Society, St. Paul, MN, USA), foi determinada a porcentagem de área lesionada de cada bráctea, representando o grau de severidade da doença. Baseando-se na lei de WeberFechner de acuidade visual (HORSFALL \& COWLING, 1978), bem como no valor máximo de severidade da doença constatada nas brácteas coletados, na forma, na distribuição e na freqüência das lesões, foi confeccionada uma escala diagramática com nove níveis de severidade.

Na validação da escala diagramática, foram utilizadas 45 brácteas de bastão do imperador com diferentes níveis de severidade da antracnose, e reproduzidas em fotocópias coloridas. A severidade foi avaliada por dez pessoas (A a J) sem experiência na quantificação da doença. Inicialmente, a severidade foi estimada sem o auxílio da escala diagramática e, após sete dias, foi realizada uma primeira avaliação com o auxílio da escala. Visando avaliar a repetibilidade das estimativas com a escala diagramática, sete dias após a primeira avaliação, uma nova seqüência das mesmas folhas foi organizada e uma segunda estimativa visual com auxílio da escala foi efetuada pelos mesmos avaliadores.

A acurácia e a precisão de cada avaliador foram determinadas por regressão linear simples, com a severidade real obtida eletronicamente como variável independente e a severidade estimada pelo avaliador como variável dependente. A acurácia das estimativas de cada avaliador e do conjunto de avaliadores foi determinada pelo teste $t$ aplicado ao intercepto da regressão linear ( $a$ ), para verificar a hipótese Ho: $a=0$, e ao coeficiente angular da reta $(b)$, para testar a hipótese Ho: $b=1$, ao nível de $5 \%$ de probabilidade de erro. A precisão das estimativas foi determinada pelo coeficiente de determinação da regressão $\left(r^{2}\right)$, pela variância dos erros absolutos (severidade estimada menos severidade real) e pela repetibilidade das estimativas, determinada pela regressão da segunda avaliação em relação à primeira de uma mesma unidade amostral. A reprodutibilidade das estimativas foi determinada pelos valores de $r^{2}$ obtidos de regressões lineares entre as severidades estimadas da mesma unidade amostral por diferentes avaliadores combinados em pares (NUTTER JR \& SCHULTZ, 1995).

O valor máximo de severidade da antracnose verificado nas 100 brácteas de bastão do imperador foi de $91,8 \%$, enquanto o valor mínimo foi de $1,08 \%$, e a média foi de 23,2\%. A escala diagramática elaborada para quantificação da severidade da doença foi representada pelos valores de 1, 2, 4, 8, 16, 32, 64, 82 e $92 \%$ de área da bráctea lesionada (Figura 1). Na primeira etapa de validação da escala diagramática, ou seja, sem a sua utilização, os valores do intercepto de $80 \%$ dos avaliadores diferiram significativamente de zero para as retas de regressão entre a severidade real e a estimada (Tabela 1). A maioria dos avaliadores superestimou a severidade da antracnose, sendo que, na média dos avaliadores, o valor do intercepto foi de 4,12 e diferiu significativamente de zero (Tabela 1 ). Com a utilização da escala, os valores do intercepto de $40 \%$ dos avaliadores (A, B, F e H) diferiram significativamente de zero na primeira avaliação e $30 \%$ (A, B e F) na segunda, sendo que todos com desvios negativos. Os valores do coeficiente angular da reta de $30 \%$ dos avaliadores diferiram significativamente de 1 sem a utilização da escala diagramática, enquanto que com a utilização da escala nenhum dos avaliadores apresentou coeficiente angular diferente de 1 nas duas avaliações (Tabela 1).

A análise da precisão das estimativas visuais da severidade sem a utilização da escala diagramática 


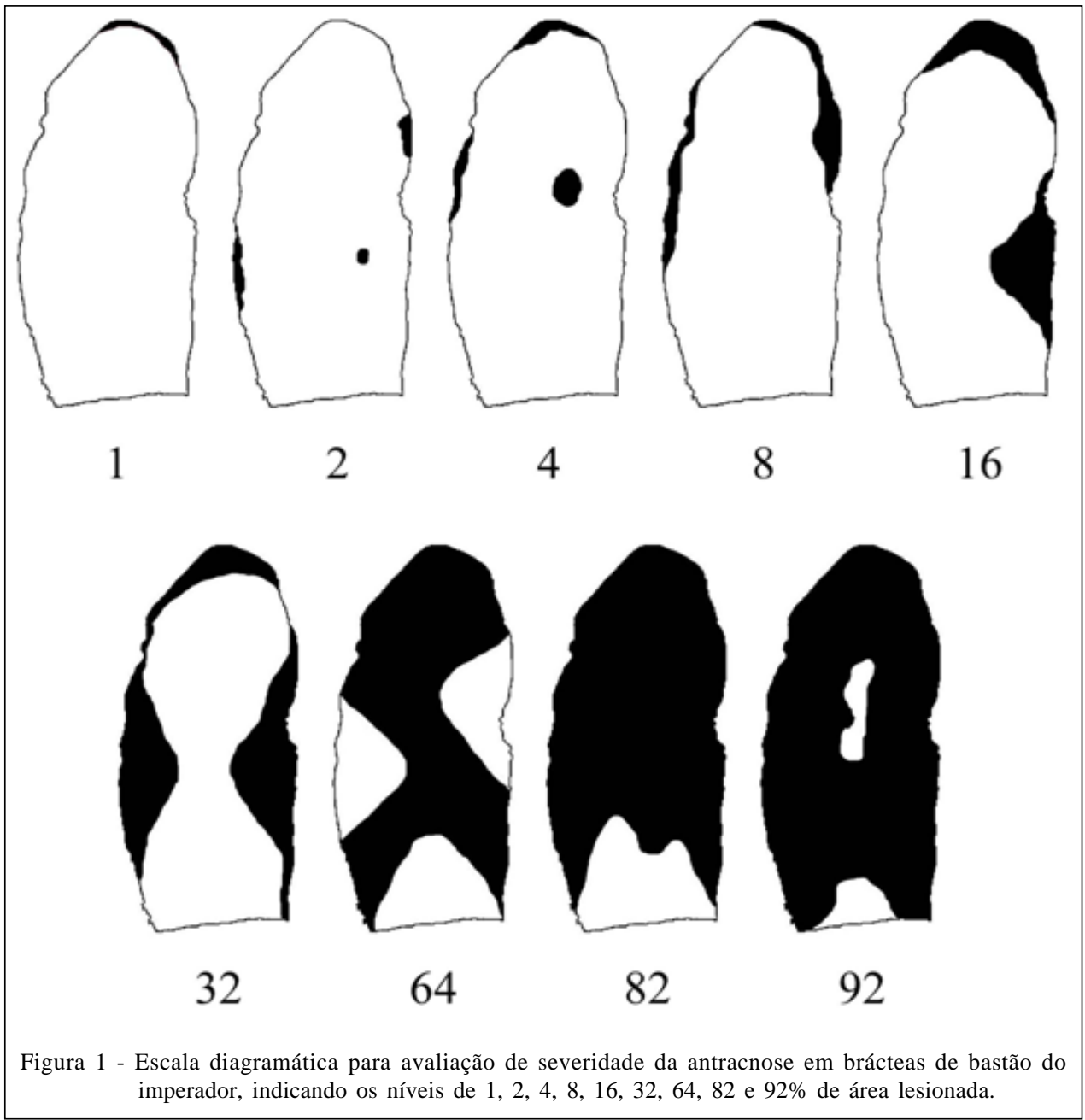

justificou de 72 a $89 \%$ da variação $\left(r^{2}\right)$ na mensuração eletrônica da doença, com média de 84\% (Tabela 1). Com a utilização da escala, na primeira avaliação, as estimativas visuais explicaram 91 a 95\% da variação na mensuração eletrônica, com média de 93\%, enquanto que na segunda avaliação, as estimativas visuais explicaram 93 a 97\% da variação, com média de 95\%. Os elevados níveis de precisão das estimativas visuais da antracnose em bastão do imperador com auxílio da escala diagramática assemelham-se aos níveis verificados em estudos recentes de validação de escalas (BARBOSA et al., 2006; GODOY et al., 2006). A maioria dos avaliadores obteve excelente repetibilidade nas estimativas com a escala diagramática, pois a quantidade média de variação na primeira avaliação explicada pela segunda avaliação foi de 95\%.

Houve redução nos erros absolutos para as estimativas com o auxílio da escala diagramática, quando comparada com a distribuição dos resíduos das estimativas obtidas sem a escala. Nas duas avaliações com o auxílio da escala, os resíduos concentraram-se na faixa de $10 \%$, números considerados aceitáveis em estudos de avaliação de escalas diagramáticas, e que podem ser reduzidos com o treinamento dos avaliadores (NUTTER JR \& SCHULTZ, 1995). Por outro lado, sem a utilização da escala, os erros concentraram-se na faixa de $25 \%$, sendo considerados elevados.

Sem a utilização escala diagramática, em somente $6,7 \%$ dos casos, a reprodutibilidade das estimativas da severidade da doença foi $\geq 90 \%$, enquanto que com o uso da escala diagramática esse nível foi atingido em 75,6\% dos casos na primeira avaliação e 91,1\% dos casos na segunda.

A escala diagramática proposta para quantificação da severidade da antracnose em bastão do imperador propiciou melhoria significativa nos níveis de acurácia, precisão e reprodutibilidade das estimativas, podendo ser utilizada em estudos epidemiológicos e de comparação de medidas de controle da doença.

Ciência Rural, v.38, n.3, mai-jun, 2008. 
Tabela 1 - Acurácia e precisão representadas pelo intercepto (a), coeficiente angular da reta (b) e coeficiente de determinação ( $\mathrm{r}^{2}$ ) de equações de regressão linear simples nas avaliações da severidade de antracnose em bastão do imperador efetuadas por 10 avaliadores, sem e com o auxílio da escala diagramática.

\begin{tabular}{|c|c|c|c|c|c|c|c|c|c|}
\hline \multirow{3}{*}{ Avaliador } & \multicolumn{3}{|c|}{--------Sem escala-------- } & & \multicolumn{4}{|c|}{ 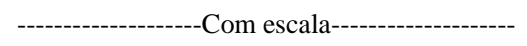 } & \multirow{3}{*}{----} \\
\hline & \multirow[b]{2}{*}{$\mathrm{a}$} & \multirow{2}{*}{$\mathrm{b}$} & \multirow{2}{*}{$r^{2}$} & \multicolumn{3}{|c|}{----------1 ${ }^{\text {a }}$ avaliação----------- } & \multicolumn{2}{|c|}{----------2ª avaliação----------- } & \\
\hline & & & & a & b & $\mathrm{R}^{2}$ & $\mathrm{a}$ & $\mathrm{b}$ & \\
\hline A & $12,63^{*}$ & $0,81^{*}$ & 0,74 & $-6,29 *$ & 1,03 & 0,91 & $-3,83 *$ & 0,99 & 0,94 \\
\hline B & $2,59 *$ & 1,05 & 0,87 & $-5,19 *$ & 1,03 & 0,92 & $-4,42 *$ & 1,04 & 0,95 \\
\hline $\mathrm{C}$ & $4,47 *$ & $1,14^{*}$ & 0,72 & 0,12 & 1,05 & 0,92 & 0,13 & 1,04 & 0,93 \\
\hline $\mathrm{D}$ & $3,31^{*}$ & 0,97 & 0,83 & 0,77 & 1,03 & 0,93 & 1,92 & 1,04 & 0,96 \\
\hline $\mathrm{E}$ & 1,81 & 0,97 & 0,88 & 0,12 & 1,00 & 0,94 & 0,35 & 0,99 & 0,95 \\
\hline $\mathrm{F}$ & $-2,13$ & $0,87^{*}$ & 0,89 & $-4,50 *$ & 0,95 & 0,94 & $-3,82 *$ & 0,97 & 0,95 \\
\hline G & $9,40^{*}$ & 0,96 & 0,82 & $-0,82$ & 0,99 & 0,94 & $-0,35$ & 0,98 & 0,94 \\
\hline $\mathrm{H}$ & $-4,48^{*}$ & 0,97 & 0,88 & $-4,33^{*}$ & 1,05 & 0,95 & $-2,09$ & 1,02 & 0,97 \\
\hline I & $4,42 *$ & 1,05 & 0,89 & 1,25 & 1,02 & 0,94 & 1,91 & 1,05 & 0,96 \\
\hline $\mathrm{J}$ & $9,13^{*}$ & 0,96 & 0,88 & 0,83 & 1,00 & 0,93 & 0,48 & 0,99 & 0,96 \\
\hline Média & $4,12^{*}$ & 0,98 & 0,84 & $-1,80$ & 1,02 & 0,93 & $-0,97$ & 1,01 & 0,95 \\
\hline
\end{tabular}

*Asterisco representa situações onde a hipótese de nulidade $(a=0$ ou $b=1)$ foi rejeitada pelo teste $t(P=0,05)$.

\section{REFERÊNCIAS}

BARBOSA, M.A.G. et al. Elaboração e validação de escala diagramática para avaliação da severidade da ferrugem branca do crisântemo. Summa Phytopathologica, v.32, n.1, p.5762, 2006.

BERGAMIN FILHO, A.; AMORIM, L. Doenças de plantas tropicais: epidemiologia e controle econômico. São Paulo: Agronômica Ceres, 1996. 299p.

GODOY, C.V. et al. Diagrammatic scale for assessment of soybean rust severity. Fitopatologia Brasileira, v.31, n.1, p.63-68, 2006.
HORSFALL, J.G.; COWLING, E.B. Pathometry: the measurement of plant disease. In: HORSFALL, J.G.; COWLING, E.B. (Ed.). Plant disease: an advanced treatise - how disease develops in populations. New York: Academic, 1978. v.2, p.119-136.

LINS, S.R.O.; COELHO, R.S.B. Antracnose em inflorescências de bastão do imperador (Etlingera elatior): ocorrência e métodos de inoculação. Summa Phytopathologica, v.29, n.4, p.355358, 2003.

NUTTER JR., F.W.; SCHULTZ, P.M. Improving the accuracy and precision of disease assessments: selection of methods and use of computer-aided training programs. Canadian Journal of Plant Pathology, v.17, n.1, p.174-184, 1995. 